\title{
A Contabilidade Gerencial nos Eventos EnAnpads de 2004 a
} 2008

Adriana Maria Rocha
Mestrado em andamento em Administração pela Faculdade Novos Horizontes - FNH
Professora da Faculdade Novos Horizontes - FNH
Rua Nascimento, 101. Belo Horizonte/MG. CEP: $30620-390$
E-mail: adrianamrocha@oi.com.br
Elisson Alberto Tavares Araújo Mestrado em andamento em Administração pela Faculdade Novos Horizontes - FNH Rua Alvarega Peixoto, 1270 (FNH). Belo Horizonte/MG. CEP: 30180-121 E-mail: elisson_alberto@yahoo.com.br

Wendel Alex Castro Silva Doutorado em Administração pela Universidade Federal de Lavras - UFLA, Professor da Faculdade Novos Horizontes - FNH Rua Alvarega Peixoto, 1270 (FNH/NUPEC). Belo Horizonte/MG. CEP: 30180-121 E-mail:wendel.silva@unihorizontes.br

\section{RESUMO}

As pesquisas em Contabilidade Gerencial (CG) publicadas nos periódicos internacionais, nos últimos dez anos, apontam para o tema Sistema de Controle Gerencial (SCG) como o preferido pelos seus autores. Com vistas a relevância desses estudos desenvolvidos nesta área do conhecimento, buscou-se explicitar as áreas e os temas onde está concentrada a maioria das pesquisas em CG nos eventos EnANPADs de 2004 até 2008. Fez-se uma pesquisa bibliométrica descritiva, quantitativa e longitudinal, com a aplicação da Lei de Zipf , e utilizou-se a elaboração teórica de Shields (1997), a qual permitiu a classificação dessas pesquisas em tipologias e subtipologias. Desta feita, verificou-se que o tema acima também foi o predominante para os autores brasileiros nos 195 artigos avaliados, seguindo-se uma tendência de replicar os estudos internacionais. Houve, ainda, uma diminuição das publicações em CG no último Encontro, sobretudo, da tipologia SCG. Em contrapartida, a tipologia "outros", que abrange novas áreas da CG, vem crescendo desde de 2005, o que permite concluir que os pesquisadores brasileiros têm explorado mais essas áreas que estão surgindo.

Palavras-chave: Bibliometria. Contabilidade Gerencial. EnANPAD

The Management Accounting in the Events EnAnpads from 2004 until 2008 
A Contabilidade Gerencial nos Eventos EnAnpads de 2004 a 2008

Adriana Maria Rocha, Elisson Alberto Tavares Araújo, Wendel Alex Castro Silva

\section{ABSTRACT}

The research in Management Accounting (MA) published in periodic the international ones in last the ten years, points respect to the subject System of Control Management Control (SCM) how the preferred for your authors. With sights the relevance of these studies developed in this area of the knowledge, searched to quote the areas and the subjects where the majority of the research in MA in the EnANPADs events of 2004 until 2008. The descriptive, quantitative and bibliometry research became and longitudinal, with the application of the Law of Zipf and, it was used theoretical elaboration of Shields (1997), which it allowed to the classification of these research in typelogys and subtypelogys. Of this making, we verify that the subject above also was the predominant one for the Brazilian authors in 195 evaluated articles. This corroborates that in Brazil it is followed trend to talk back the international studies. It had, still, a reduction of publications in MA in the last Event, over all, of tipologia SCM. On the other hand, the typelogy "others", which encloses new areas of the MA, comes growing since of 2005, what in it makes them to conclude that the Brazilian researchers have explored plus these areas that are appearing.

Keywords: Bibliometry. Management Accounting. EnANPAD

\section{INTRODUÇÃO}

Faro e Silva (2008) analisaram 239 artigos publicados nos 5 principais periódicos em Contabilidade Internacional, sobre o tema Contabilidade Gerencial (CG). O periódico mais proeminente em número de publicações nesta área é o Accounting, Organizations and Society (AOS), publicação Britânica, com 113 textos no período de 1997 à maio de 2007, seguido do The Accounting Review (AR) com 43 textos e o Journal of Accounting and Economics com 33 textos.

A partir do resultado da pesquisa destes autores, surge a pergunta: qual a natureza da pesquisa em CG nos artigos publicados no Encontro Nacional da Associação de Pós-Graduação e Pesquisas em Administração - EnANPAD, nos últimos 5 anos? Portanto, a pesquisa justifica-se, tendo em vista o levantamento bibliométrico dos temas/áreas de pesquisas publicados no Brasil e ao mesmo tempo pela comparação entre os resultados obtidos nos periódicos internacionais com os do EnANPAD.

Anthony (1979) afirma que a CG tem foco na informação contábil que é importante aos administradores. Por isso o campo de pesquisa nesta área do 
conhecimento está vez cada mais interdisciplinar, já que as informações se complementam, possibilitando uma tomada de decisão mais consistente. ludícibus (1998) considera que a CG está exclusivamente orientada para a administração da organização, buscando fornecer informações que tenham validade efetiva diante do processo decisório do administrador.

A partir dos estudos internacionais, ludícibus (1998) expõe que a CG predomina nos textos americanos, e tem como principal preocupação o usuário da informação contábil. A contabilidade é sempre utilizada e apresentada como algo útil para a tomada de decisões. Esta afirmação pode ser identificada também nas características das pesquisas brasileiras, que tendem a seguir as mesmas premissas.

Conforme Padoveze (2004), apesar de a CG utilizar-se de temas de outras disciplinas, ela se caracteriza por ser uma área contábil autônoma, pelo tratamento dado à informação contábil, enfocando planejamento, controle e tomada de decisão, e por seu caráter integrativo dentro de um sistema de informação contábil. De acordo com o Instituto dos Auditores Independentes do Brasil - IBRACON (2007), a atual fase da contabilidade é a gerencial, diretamente ligada ao capitalismo industrial. Surgiu da demanda por gerenciamento contábil interno devido aos complexos processos de produção, a fim de se obter informações para o processo decisório. Alterou-se o enfoque da contabilidade nos registros e análises das operações financeiras, para a utilização estratégica da informação como suporte às decisões que buscam 0 crescimento da organização.

Segundo Padoveze (apud FRANCIA, 2004), a CG é considerada como um processo constituído pelas fases de identificação, mensuração, acumulação, análise, preparação, interpretação e comunicação de informações financeiras, as quais são utilizadas pela administração da organização, a fim de exercer o planejamento, avaliação e controle, visando garantir e contabilizar o uso adequado de seus recursos. Analisando as características das informações gerenciais aplicadas nas organizações, Arena (1999) apresenta o Quadro a seguir: 
A Contabilidade Gerencial nos Eventos EnAnpads de 2004 a 2008

Adriana Maria Rocha, Elisson Alberto Tavares Araújo, Wendel Alex Castro Silva

\begin{tabular}{|c|c|}
\hline \multicolumn{2}{|c|}{ Característica da Informação Contábil Gerencial } \\
\hline Útil & Atender às necessidades dos usuários \\
\hline Oportuna & Estar à disposição na época certa \\
\hline Clara & Facilmente entendida pelo usuário \\
\hline Íntegra & Baseada em dados confiáveis \\
\hline Relevante & Abordar diretamente os pontos fundamentais, com transparência \\
\hline Flexível & Apresentar-se de várias formas e na linguagem do usuário \\
\hline Completa & Incorporar dados físicos e outros complementares à informação \\
\hline Preditiva & Fornecer indicadores de tendência \\
\hline
\end{tabular}

Quadro 1 - Características da Informação Contábil Gerencial

Fonte: Arenas, 1999.

Perez Junior (1997) assinala que a tomada de decisão é influenciada pelo suporte dado pela Controladoria às informações de planejamento e controle. Estas últimas necessitam de sistemas de informações que fundamentam estas decisões. Assim, a Controladoria busca otimizar os resultados econômicos da organização com um sistema de informações apropriado ao modelo de gestão.

Com efeito, o presente artigo visa identificar em que áreas/temas de CG estão concentradas as publicações de artigos nos eventos EnANPAD entre 2004 à 2008, utilizando a técnica de pesquisa bibliométrica, que pode ser entendida como os estudos que buscam mensurar os processos de comunicação escrita. (PRITCHARD apud GUEDES; BORSCHIVER, 2005).

Esta pesquisa está estruturada da seguinte forma: após esta introdução, onde se contextualiza o tema, apresenta-se o objetivo e alguns conceitos; segue a metodologia utilizada e em seguida a análise dos resultados. Finaliza-se com as considerações finais, além das referências.

\section{ESTUDOS SOBRE CONTABILIDADE E CONTABILIDADE GERENCIAL NO BRASIL}

O Quadro 2 apresenta algumas pesquisas com ênfase em contabilidade, sobretudo, orientadas para levantamentos bibliométricos. Cada pesquisador analisa diferentes aspectos em busca de conhecer as produções científicas em contabilidade e, também, CG, seja em eventos importantes, seja em periódicos brasileiros reconhecidos pela alta qualidade, os 
A Contabilidade Gerencial nos Eventos EnAnpads de 2004 a 2008 Adriana Maria Rocha, Elisson Alberto Tavares Araújo, Wendel Alex Castro Silva

quais, por essência, selecionam os melhores trabalhos da área. Dessa forma, as pesquisas que buscam identificar o perfil das publicações brasileiras, têm se concentrado em periódicos e eventos da maior relevância. 
A Contabilidade Gerencial nos Eventos EnAnpads de 2004 a 2008

Adriana Maria Rocha, Elisson Alberto Tavares Araújo, Wendel Alex Castro Silva

\begin{tabular}{|c|c|c|}
\hline Autor(es) & Objetivo(s) & Considerações/Conclusão \\
\hline $\begin{array}{l}\text { Oliveira } \\
\text { (2002) }\end{array}$ & $\begin{array}{c}\text { Analisar as características dos } \\
\text { Periódicos Brasileiros de } \\
\text { Contabilidade }\end{array}$ & $\begin{array}{c}\text { Evidenciou-se uma mudança no paradigma contábil, } \\
\text { para o foco na CG e assuntos pertinentes à ela. } \\
\text { Percebeu-se a carência de publicações sobre } \\
\text { Contabilidade Internacional, Contabilidade e } \\
\text { Mercado de Capitais e contabilidade Social e } \\
\text { Ambiental } \\
\end{array}$ \\
\hline $\begin{array}{c}\text { Kroenke e } \\
\text { Cunha (2003) }\end{array}$ & $\begin{array}{l}\text { Verificar as publicações sobre } \\
\text { harmonização contábil, no } \\
\text { período de } 2004 \text { a 2007, em } \\
\text { eventos nacionais de } \\
\text { classificação A Qualis/Capes }\end{array}$ & $\begin{array}{l}\text { Os eventos com a maior concentração de artigos } \\
\text { coletados e selecionados com as palavras-chave } \\
\text { harmonização, padronização, convergência e } \\
\text { normatização foram do EnANPAD, três artigos } \\
\text { analisados foram do Congresso USP de } \\
\text { Controladoria e Contabilidade e um do EnANPAD }\end{array}$ \\
\hline $\begin{array}{l}\text { Mendonça } \\
\text { Neto et al. } \\
\text { (2004) }\end{array}$ & $\begin{array}{c}\text { Analisar a distribuição, as } \\
\text { características metodológicas, } \\
\text { a evolução, a temática e a } \\
\text { produtividade dos autores das } \\
\text { publicações em contabilidade } \\
\text { entre } 1990 \text { à } 2003 \text {, nos } \\
\text { periódicos nacionais A } \\
\text { Qualis/Capes }\end{array}$ & $\begin{array}{l}\text { As IES com maior numero de publicações foram: } \\
\text { USP, FGV-SP, FGV-RJ e UFRGS. O Estado de São } \\
\text { Paulo teve } 51,1 \% \text { dos artigos publicados. Já o } \\
\text { número de autores com uma só publicação é maior } \\
\text { do que o indicado por outros trabalhos. }\end{array}$ \\
\hline $\begin{array}{c}\text { Leite Filho } \\
(2006)\end{array}$ & \begin{tabular}{|c|} 
Analisou a produtividade \\
científica dos autores em anais \\
de congressos e periódicos de \\
contabilidade brasileiros
\end{tabular} & $\begin{array}{c}\text { Nos periódicos a ênfase é em estudos de autoria } \\
\text { singular e nos anais de congressos, em co-autoria. A } \\
\text { maioria dos autores são masculinos. Há indícios de } \\
\text { endogenia de instituições nacionais, concentração } \\
\text { de autoria vinculada a poucas instituições e, os } \\
\text { autores mais prolíficos apresentam mais de } 26 \% \\
\text { dos artigos }\end{array}$ \\
\hline $\begin{array}{l}\text { Cardoso et al. } \\
(2007)\end{array}$ & \begin{tabular}{|c|} 
Traçar um perfil da pesquisa \\
em custos sobre contabilidade \\
e controle gerencial do \\
EnANPAD, desde a sua \\
inauguração como área \\
autônoma em 1998 até 2000
\end{tabular} & $\begin{array}{l}\text { Houve um grande aumento da quantidade de artigos } \\
\text { sobre contabilidade, o que refletiu diretamente no } \\
\text { crescimento da área de custos. Contanto, não } \\
\text { ocorreu crescimento qualitativo das pesquisas sobre } \\
\text { custos. Tal artigo apresenta o estado da arte da } \\
\text { pesquisa em contabilidade de custos no EnANPAD. }\end{array}$ \\
\hline $\begin{array}{l}\text { Albuquerque } \\
\text { et al. (2008) }\end{array}$ & $\begin{array}{l}\text { Discutir a controvérsia do } \\
\text { paradigma econômico na } \\
\text { pesquisa empírica em CG } \\
\text { proposta por Zimmerman e } \\
\text { criticada por alguns } \\
\text { pesquisadores }\end{array}$ & $\begin{array}{l}\text { Notou-se um consenso entre os debatedores, que o } \\
\text { paradigma econômico isoladamente não responde } \\
\text { às questões da CG, haja vista a complexidade do } \\
\text { ambiente em que a mesma encontra-se inserida. }\end{array}$ \\
\hline $\begin{array}{l}\text { Faro e Silva } \\
\quad(2008)\end{array}$ & $\begin{array}{l}\text { Mapear a produção acadêmica } \\
\text { internacional em CG, e } \\
\text { observar o aparecimento de } \\
\text { novas áreas de pesquisa em } \\
\text { CG, após } 1996\end{array}$ & $\begin{array}{c}\text { Constatou-se que houve um aumento das pesquisas } \\
\text { que abordam SCG, além do aparecimento e } \\
\text { publicações de novas áreas }\end{array}$ \\
\hline
\end{tabular}

Quadro 2 - Estudos sobre Contabilidade e Contabilidade Gerencial no Brasil Fonte: Elaborado pelos Autores 
A Contabilidade Gerencial nos Eventos EnAnpads de 2004 a 2008

Adriana Maria Rocha, Elisson Alberto Tavares Araújo, Wendel Alex Castro Silva

Percebe-se que há pesquisas sobre CG divulgadas em periódicos e eventos nacionais, com diversos focos, ensejando a realização de pesquisas bibliométricas nesse campo, visando retratar aspectos relacionados à produção científica, o que permite comparar os resultados com estudos internacionais, como o realizado por Faro e Silva (2008).

\section{PROCEDIMENTOS METODOLÓGICOS}

Desde 1976 a ANPAD promove o ensino, a pesquisa e a produção de conhecimento da área das ciências administrativas e afins, e hoje representa um importante órgão de interação entre programas de pós-graduação, grupos de pesquisa e a comunidade internacional. Esta entidade realiza a cada ano o Encontro Científico de Administração (EnANPAD), e conta na área de contabilidade com uma sub-área onde são apresentados e discutidos artigos relacionados com a temática da Contabilidade Gerencial, que passou a ter um grupo próprio a partir do encontro realizado em 2005.

Utilizou-se a lei de Zipf da bibliometria, a qual possibilita estimar as freqüências com que as palavras aparecem em um texto científico e tecnológico e o local de concentração de termos de indexação ou palavras-chave (GUEDES; BORSCHIVER, 2005). De posse de todos os artigos publicados nos últimos 5 anos no evento EnANPAD, identificou-se por meio da leitura dos resumos e, quando necessário, dos trabalhos na íntegra, a linha de pesquisa em CG na qual estes se enquadravam.

Como acrescenta Campos (2004), tais indicadores bibliométricos têm por objetivo apenas avaliar os impactos científicos, sem avaliar a qualidade. Contudo, são úteis como ferramenta adicional para avaliar ou definir os rumos de uma pesquisa.

Foi realizada uma pesquisa descritiva e quantitativa, utilizando a técnica de bibliometria, para identificar nos resumos dos 195 trabalhos publicados nos EnANPADs, no corte longitudinal entre 2004 a 2008, as áreas/temas de estudos em CG, agrupandoos de acordo com a tipologia de estudos de Shields (1997). A técnica de bibliometria foi aplicada como instrumento de estatística básica na gestão da informação e do conhecimento científico e tecnológico, de acordo com Guedes e Borschiver (2005), a 
qual contribuiu para a seleção dos artigos. A ferramenta MS Excel foi utilizada na organização e compilação dos mesmos. Conforme Faro e Silva (2008), a CG compreende estudos em diversos tópicos: Sistemas de Controle Gerencial (SCG); Contabilidade de Custos; Gerenciamento de Custos; Informações e Sistemas Gerenciais Contábeis e Orçamento de Capital e Decisão de Investimento. Estes tópicos apresentam-se como os principais temas de pesquisa encontrados nos artigos sobre CG pesquisados por Shields (1997), abrangendo o período de 1990 a 1996.

Seguindo esta linha de raciocínio, seguiu-se a tipologia e sub-tipologia determinadas por Shields (1997), conforme Quadro 3. Portanto, a classificação dos tópicos de pesquisa em CG de cada artigo foi feita seguindo a mesma taxonomia encontrada no trabalho de Shields (1997), descrita no Quadro 3.

\begin{tabular}{|c|c|}
\hline \multicolumn{2}{|c|}{ PESQUISA EM CONTABILIDADE GERENCIAL } \\
\hline TIPOLOGIA & SUB TIPOLOGIA \\
\hline Sistemas de Controle Gerencial & Incentivos \\
\hline & Orçamento \\
\hline & Avaliação de desempenho \\
\hline & Preço de transferência \\
\hline & Contabilidade por centro de responsabilidade \\
\hline & Controle internacional \\
\hline Contabilidade de Custos & Contabilidade de custos geral \\
\hline & Alocação de custos \\
\hline & $\mathrm{ABC}$ \\
\hline & Custo de produto \\
\hline & Variação de custos \\
\hline Gerenciamento de Custos & Qualidade \\
\hline & JIT (just in time) \\
\hline & Custos na tomada de decisão \\
\hline & Benchmarking \\
\hline & História \\
\hline Gerador de Custos & \\
\hline $\begin{array}{c}\text { Informações e Sistemas de Contabilidade } \\
\text { Gerencial }\end{array}$ & Métodos de pesquisa \\
\hline $\begin{array}{l}\text { Orçamento de Capital e Decisão de } \\
\text { Investimentos }\end{array}$ & \\
\hline
\end{tabular}

Quadro 3 - Tipologia de Shields

Fonte: Shields, 1997.

Em primeiro lugar fez-se a leitura dos resumos dos artigos selecionados, coletando-se informações sobre a quantidade de autores e classificando-os segundo os 
tópicos, métodos e técnicas de pesquisa utilizadas. Nos casos em que o resumo não permitiu a obtenção das informações necessárias para a classificação, o conteúdo do artigo foi consultado.

\section{ANÁLISE E DISCUSSÃO DOS RESULTADOS}

Foram examinados todos os resumos dos 68 artigos publicados no EnANPAD 2004; 31 em 2005; 32 em 2006; 38 em 2007 e 26 em 2008, totalizando 195 trabalhos (Gráfico 1).

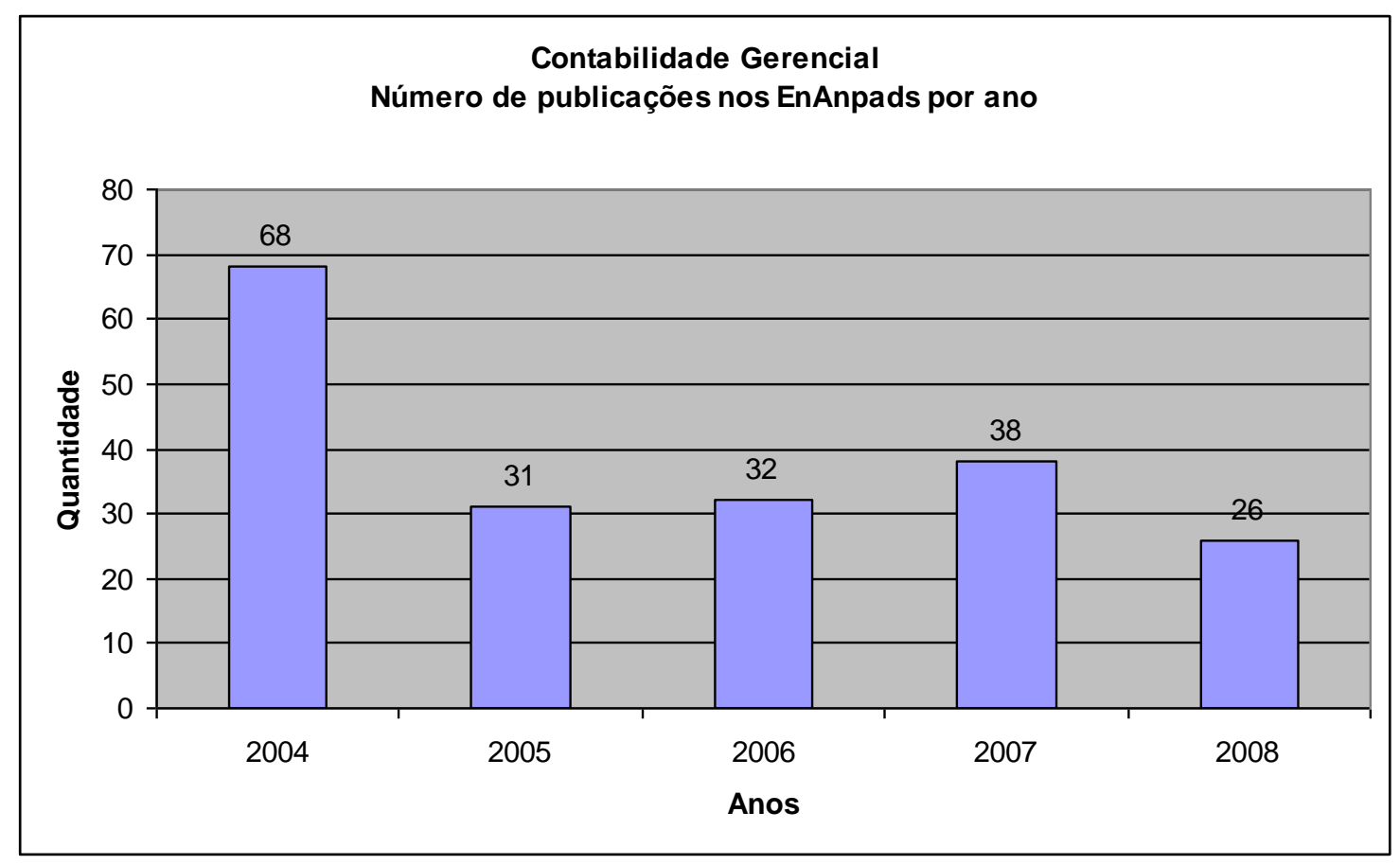

Gráfico 1 - Número de artigos sobre CG publicados nos EnAnpads de 2004 a 2008 Fonte: Dados da pesquisa.

Em 2004 a quantidade de artigos publicados no EnANPAD é $54,4 \%$ maior do que em 2005, ou seja, o equivalente a 37 trabalhos. Porém, tal comparação fica prejudicada devido a não existência da separação das seções de Contabilidade nesta edição do evento. Já em 2005, com a devida distinção entre as áreas, foram aprovados 31 trabalhos (16\%). No Encontro de 2006 foi apresentado apenas um trabalho a mais do 
que no ano anterior, ou seja, uma variação de 3,2\%. Foram apresentados 32 artigos, permanecendo o mesmo percentual de participação em relação ao total (16\%). Em 2007 aconteceu um acréscimo de 6 publicações, ou seja, uma variação de 18,7\% na relação com o ano anterior, totalizando 38 artigos (19\%). Já no último ano examinado ocorreu um decréscimo acentuado da ordem de $31,6 \%$, ou seja, houve uma redução de 12 artigos.

No que se refere à tipologia de pesquisa em CG mais abordada no período em questão (Gráfico 2), percebe-se que há uma preferência por artigos sobre Sistemas de Controle Gerencial SCG, com 40\% dos artigos no ano de 2004, 30\% em 2005, 20\% em 2006, 35\% em 2007 e 40\% em 2008, perfazendo uma média de 38\%. Em segundo lugar, a pesquisa revela uma maior concentração em artigos sobre Contabilidade de Custos, com 10\% em 2004, 15\% em 2005, 40\% em 2006, 25\% em 2007 e 14\% em 2008, ou seja, uma média de 19\%. Esses resultados revelam uma tendência dos estudos brasileiros seguirem a mesma linha de pesquisa dos artigos publicados nos periódicos internacionais, conforme resultados da pesquisa de Faro e Silva (2008).

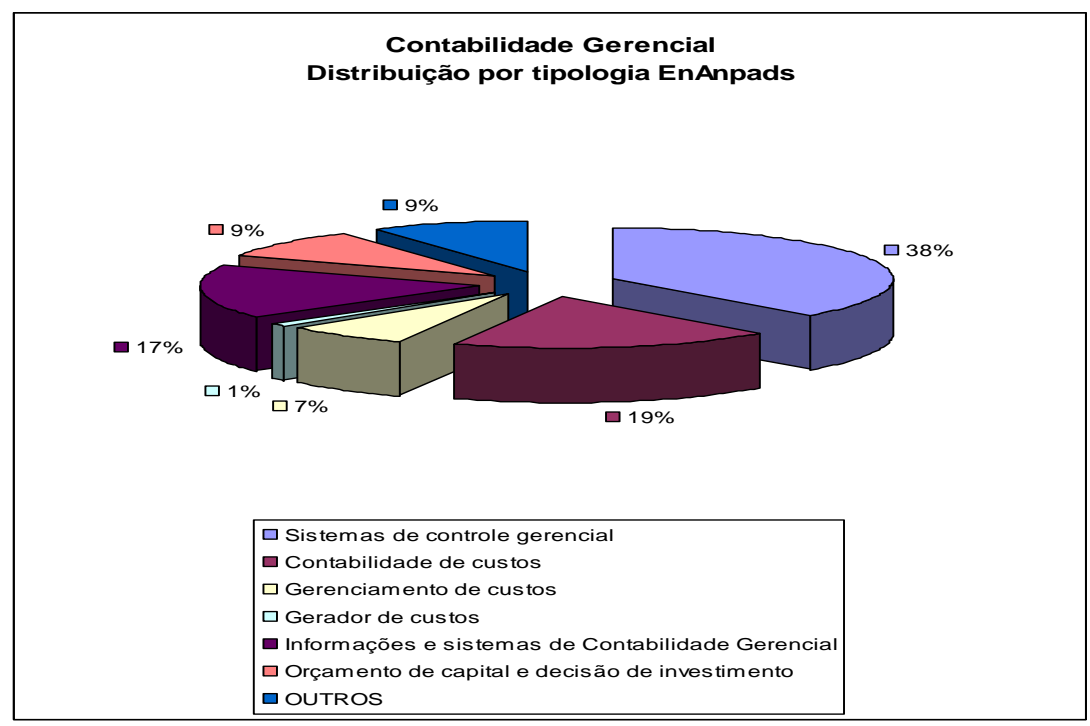

Gráfico 2 - Distribuição dos artigos por Tipologia Fonte: Dados da pesquisa. 
Em $80 \%$ dos anos estudados (quatro dos cinco anos), pode-se constatar a predominância da tipologia SCG como foco das pesquisas publicadas nos EnANPADs. Em 2004 ela representou pouco mais de 40\% dos trabalhos. Já em 2005, aproximadamente $32 \%$. Apenas no ano de 2006, quando não esteve no cerne das pesquisas, caiu para 25\%. Contanto, teve um salto significativo em 2007 chegando a quase $40 \%$ do total em CG. Em 2008 chegou a representar 42\%, havendo uma redução na quantidade física de artigos em relação ao ano anterior, porém houve um aumento de $2 \%$ da participação na quantidade total, ainda que esta tenha diminuído na comparação com 2007.

Com efeito, os resultados desta pesquisa assim como os da pesquisa realizada por Faro e Silva (2008) em relação às divulgações de artigos sobre CG em periódicos internacionais, apresenta resultados distintos dos apurados por Albuquerque et al. (2008), os quais mencionam que Zimmerman relata haver um enfoque praticamente exclusivo da literatura empírica em CG sobre o processo decisório em detrimento do controle.

Enquanto Albuquerque et al. (2008) apontam para o predomínio na pesquisa de Zimmerman acerca de produções científicas na temática de "tomada de decisão", a pesquisa sobre publicações internacionais de Faro e Silva (2008), e esta baseada nos encontros da ANPAD, corroboram a tipologia SCG como a abordagem preponderante, seja entre pesquisadores estrangeiros, seja entre autores brasileiros, prosseguindo a tendência destes últimos continuarem a replicar estudos internacionais. Os temas mais novos de CG dão mostras de que vêm despertando maior interesse por parte dos pesquisadores, uma vez que vêm aumentando gradativamente o número de artigos divulgados no encontro da ANPAD.

\section{CONSIDERAÇÕES FINAIS}

O objetivo desse estudo foi examinar as áreas/temas onde está concentrada a maior parte das pesquisas no ramo do conhecimento da Contabilidade Gerencial, 
A Contabilidade Gerencial nos Eventos EnAnpads de 2004 a 2008

Adriana Maria Rocha, Elisson Alberto Tavares Araújo, Wendel Alex Castro Silva

especificamente, no que tange aos artigos publicados nos eventos EnANPADs de 2004 a 2008.

Mediante a aplicação da técnica de bibliometria, mais precisamente da Lei de Zipf, foram examinados 195 artigos sobre Contabilidade Gerencial divulgados nos cinco últimos encontros da ANPAD, percebendo-se que estes apresentam características idênticas àqueles divulgados em períodicos internacionais, ou seja, há um predomínio de artigos sobre Sistemas de Controle Gerencial (SCG).

Ainda que os artigos sobre SCG tenham sido os mais significativos na amostra, ocorreu uma redução no EnANPAD de 2008. Em contrapartida, a tipologia "outros", que abarca novas áreas da CG, vem evoluindo desde de 2005 neste evento, ainda que lentamente, revelando que os pesquisadores brasileiros estão atentos a novas áreas da CG que estão surgindo.

Novos estudos poderão ampliar e detalhar as características das pesquisas realizadas no ramo de conhecimento $C G$, seja em eventos ou periódicos nacionais, identificando áreas/temas que estão surgindo como: Mudanças em Contabilidade Gerencial, Contabilidade Horizontal, Contabilidade Estratégica, Contabilidade Organizacional, Contabilidade Virtual e Pesquisa Integrativa, apontados no estudo de Faro e Silva (2008) como tendência das publicações internacionais.

Considera-se como limitação do estudo, o não aprofundamento da pesquisa no que tange aos principais autores utilizados, as principais ferramentas de controle utilizadas nos sistemas gerenciais para a tomada de decisão, questões inerentes à estruturação dos trabalhos e de seus pesquisadores, as quais proporcionariam a configuração de um perfil mais completo relacionado às publicações de CG.

\section{REFERÊNCIAS}

ALBUQUERQUE, K. S. L. S.; GOMES, S. M. S. e SILVA, F. C. C. (2008). Discussão sobre a Controvérsia do Paradigma Econômico na Pesquisa Empírica em Contabilidade Gerencial. In: Encontro da Associação Nacional de Pós-graduação e Pesquisa em Administração, 32. Rio de Janeiro. Anais...Rio de Janeiro: ANPAD, 2008.

ANDRADE, M. M. (2006). Introdução à Metodologia do Trabalho Científico. (7 ed.). São Paulo: Atlas. 
A Contabilidade Gerencial nos Eventos EnAnpads de 2004 a 2008 Adriana Maria Rocha, Elisson Alberto Tavares Araújo, Wendel Alex Castro Silva

ANTHONY, R. N. (1979). Contabilidade Gerencial. São Paulo: Atlas.

ARENAS, M. V. S. (1999). Sistema de Informação Gerencial: Controladoria como Apoio para Tomada de Decisão - Um Estudo de Caso numa Instituição Privada de Ensino Superior. Porto Velho, ES. (Dissertação de Mestrado). Convênio Interinstitucional UNIR/UFSC, $111 \mathrm{p}$.

ASSOCIAÇÃO NACIONAL DE PÓS-GRADUAÇÃO E PESQUISA EM ADMINISTRAÇÃO (ANPAD). Disponível em: www.anpad.org.br. Acesso em: 30/ago/2008.

CARDOSO, R. L.; PEREIRA, C. A. e GUERREIRO, R. (2007). Perfil das Pesquisas em Contabilidade de Custos Apresentadas no Enanpad no Período de 1998 à 2003. Revista Administração Contemporânea. Curitiba, v. 11, n. 3, Sept.

FARO, M. C. S. C. e SILVA, R. N. S. (2008). A Natureza da Pesquisa em Contabilidade Gerencial - Análise Bibliométrica de 1997 à 2007 nos Principais Periódicos Internacionais. In: Encontro da Associação Nacional de Pós-graduação e Pesquisa em Administração, 32. Rio de Janeiro. Anais...Rio de Janeiro: ANPAD.

GUEDES, V. L. S. e BORSCHIVER, S. (2005). Bibliometria: Uma Ferramenta Estatística para a Gestão da Informação e do Conhecimento, em Sistemas de Informação, de Comunicação e de Avaliação Científica e Tecnológica. Disponível em: http://dici.ibict.br/archive/00000508/. Acesso em: 10/dez/2008.

Instituto dos Auditores Independentes do Brasil (INBRACON). (2007). Auditoria Registros de Uma Profissão. São Paulo.

IUDíCIBUS, S. (1998). Contabilidade Gerencial. (6 ed.). São Paulo: Atlas.

KROENKE, A. e CUNHA, J. V. A. Harmonização Contábil: Um Estudo Bibliométrico no Congresso Usp e Enanpad de 2004 a 2007. Disponível em: http://www.ead.fea.usp.br/semead/11semead/resultado/an_resumo.asp?cod_trabalho=7 43. Acesso em: 10/set/2008.

LEITE FILHO, G. A. Padrões de Produtividade de Autores em Periódicos e Congressos na Área de Contabilidade no Brasil: Um Estudo Bibliométrico. Disponível em: <http://www.congressousp.fipecafi.org/artigos62006/84.pdf>. Acesso em: 16/set/2008.

MENDONÇA NETO, O. C.; CARDOSO, R. L.; RICCIO, E. L. e SAKATA, M. C. G. (2004). Estudo sobre as Publicações Científicas em Contabilidade: uma Análise de 1990 até 2003. In: Encontro da Associação Nacional de Pós-graduação e Pesquisa em Administração, 28. Curitiba. Anais...Rio de Janeiro: ANPAD. 
OLIVEIRA, M. C. (2002). Análise dos Periódicos Brasileiros de Contabilidade. Revista Contabilidade \& Finanças - USP. São Paulo. n. 29, p. 68-86, maio/ago.

PADOVEZE, C. L. (2004). Contabilidade Gerencial: um Enfoque em Sistema de Informação Contábil. (4 ed.). São Paulo: Atlas.

PEREZ JUNIOR, J. H. (1997). Conversão de Demonstrações Contábeis. (6 ed.). São Paulo: Atlas.

SHIELDS, M. (1997). Research in Management Accounting by North Americans in the 1990s. Journal of Management Accounting Research. Columbus, p. 3-61 ago.

Data de Submissão: 02/03/2009

Data de Aceite: 23/04/2009 